\title{
Surface-based remote sensing of the mixing-layer height - a review
}

\author{
STEFAN EMEIS $^{1 *}$, KLAUS SCHÄFER $^{1}$ and CHRISTOPH MÜNKEL ${ }^{2}$ \\ ${ }^{1}$ Institut für Meteorologie und Klimaforschung - Bereich Atmosphärische Umweltforschung, Forschungszentrum \\ Karlsruhe GmbH, Garmisch-Partenkirchen, Germany \\ ${ }^{2}$ Vaisala GmbH, Hamburg, Germany
}

(Manuscript received March 6, 2008; in revised form June 30, 2008; accepted July 11, 2008)

\begin{abstract}
Presently available methods for the determination of the mixing-layer height from surface-based acoustic, optical and electro-magnetic remote sensing are summarized and compared. Most complete information on the structure of the ABL can be expected from a combined use of acoustic together with optical or electromagnetic remote sensing.
\end{abstract}

\begin{abstract}
Zusammenfassung
Gegenwärtig verfügbare Methoden zur Bestimmung der Mischungsschichthöhe mit bodengebundenen akustischen, optischen und elektro-magnetischen Fernerkundungsverfahren werden vorgestellt und verglichen. Der größte Informationsgewinn kann durch den parallelen Einsatz der akustischen mit der optischen oder der elektro-magnetischen Fernerkundung erwartet werden.
\end{abstract}

\section{Introduction}

The layering of the atmospheric boundary layer (ABL) due to the vertical temperature and moisture distribution and the existence of inversions within this layer or on the top of it have a strong influence on the development of episodes of high concentrations of air pollutants and noise annoyance near the Earth's surface which might be harmful to people and ecosystems. Within the ABL the height of the mixing layer (MLH) is defined as the height up to which due to the thermal structure of the ABL vertical dispersion by turbulent mixing of air pollutants takes place (SEIBERT et al., 2000; SCHÄFER et al., 2006). Due to the limiting role of the stable stratification above and the inversion at the top of the mixing layer most of the aerosol particles in an atmospheric column are usually confined to atmospheric layers below MLH, the knowledge on MLH can thus be employed to convert column-mean optical depths measured from satellites into near-surface air quality information (SIFAKIS et al., 1998; DANDOU et al., 2002; SCHÄFER et al., 2008). MLH depends heavily on the synoptic weather situation. Over level terrain in Central Europe, MLH can easily reach $2000 \mathrm{~m}$ and more above ground level in spring and summer. Both, thermal layering and MLH also influence the noise propagation. Stable thermal layering favours downward bending of sounds rays. Low elevated inversions can lead to noise ducts which can

\footnotetext{
*Corresponding author: Stefan Emeis, Institut für Meteorologie und Klimaforschung - Bereich Atmosphärische Umweltforschung, Forschungszentrum Karlsruhe GmbH, Kreuzeckbahnstr. 19, 82467 Garmisch-Partenkirchen, Germany, e-mail: Stefan.Emeis@imk.fzk.de
}

convey noise over large horizontal distances (HEIMANN et al., 2007).

The use of modern ground-based remote sensing techniques to follow the diurnal variations of the atmospheric layering and MLH seems promising. The choice is between acoustic (SODAR), optical (LIDAR, ceilometer), and electro-magnetic (Doppler radar, wind profiler) remote sensing (for the latter see also DABBERDT et al., 2004) or a suitable combination of them. Sound waves are scattered at temperature gradients (either mean or turbulent ones) in the atmosphere. Light waves are scattered at small particles (Mie scattering) or at air molecules (Rayleigh scattering). Particles may serve as good indicator of atmospheric layering because - as mentioned above - their vertical distribution is heavily influenced by the thermal structure of the atmosphere (NEFF and COULTER, 1986). Electromagnetic signals are backscattered at small-scale fluctuations of temperature and especially moisture concentrations.

An overview on methods to determine the MLH from in-situ measurements and surface-based remote sensing has been given by SEIBERT et al. (2000). Since then considerable development has taken place, especially concerning the usage of remote sensing methods. E.g. SEIBERT et al. (2000) classified lidar methods as expensive, not eye-save, with a high lowest range gate, limited range resolution, and sometimes subject to ambiguous interpretation. This has changed drastically in the last ten years when better lidars have been built and ceilometers have been discovered to be a nearly ideal boundary layer sounding instrument. Also in the field of acoustic 
sounding progress has been made. The algorithms for the determination of MLH from vertical profiles of the acoustic backscatter intensity as described in BEYRICH (1997) and SEIBERT et al. (2000) have been enhanced by using further variables available from sodar measurements such as the wind speed and the variance of the vertical velocity component (ASIMAKOPOULOS et al., 2004, EMEIS and TÜRK, 2004). Such enhancements have been named as a possible methods in BEYRICH (1995) and SEIBERT et al. (2000) but obviously no example was available at that time.

The determination of MLH from the measurements with remote sensing instruments is a specialized usage of these devices that today are frequently used for wind and turbulence measurements (for recent reviews see e.g. ENGELBART et al., 2007; EMEIS et al., 2007a).

This paper gives a new review focussing on the rapidly developing field of surface-based remote sensing since the year 2000. We will start with a short description of the refinement of MLH algorithms from acoustic sounding. A main topic will be the use of ceilometers for profiling the ABL. The combined use of sodars and ceilometers will give additional insight in the vertical structure of the ABL.

\section{MLH algorithms}

In the following subsections we will describe the algorithms with which the MLH is derived from groundbased remote sensing data (see Table 1 for a short overview). We will denote with the letter $\mathrm{H}$ and an attached number certain derived heights which are related to inversions and the MLH; while we will use the variable $\mathrm{z}$ to denote the normal vertical coordinate. We will mainly concentrate on acoustic and optical remote sensing because electro-magnetic remote sensing has too high lowest range gates for a good coverage of shallow MLH.

\subsection{Acoustic detection of MLH}

Acoustic waves are scattered at small-scale temperature fluctuations (turbulence) and at sharp mean temperature gradients (stable layers and inversions). BEYRICH (1997) has listed possible analyses which can mainly be made from acoustic backscatter intensities measured by a sodar. ASIMAKOPOULOS et al. (2004) summarized three different methods to derive MLH from sodar data: (1) the horizontal wind speed method (HWS), (2) the acoustic received echo method (ARE), and (3) the vertical wind variance method (VWV). We will follow this classification here.

\subsubsection{Acoustic received echo (ARE) method}

The ARE method is the most basic method of determining MLH from acoustic remote sensing. Most of the methods listed in BEYRICH (1997) belong to this method. The method does not require an analysis of the Doppler shift of the backscattered signals. MLH is analyzed either from the maximum negative slope or from the changing curvature of the vertical profile of the acoustic backscatter intensity or it is analyzed from the height where the backscatter intensity decreases below a certain pre-specified threshold value. The method can be enhanced in two ways. The first way is to include further variables into the MLH algorithm that are available from Doppler-SODARs. The additional usage of the variance of the vertical velocity component has been demonstrated by EMEIS and TÜRK (2004). The second way to enhance the ARE method is to determine not only MLH from sodar measurements but also the height of lifted inversions. Especially in orographically complex terrain the vertical structure of the ABL can be very complicated. EMEIS et al. (2007b) have shown that several persistent inversions one above the other which form in deep Alpine valleys can be detected from sodar measurements. An enhanced ARE method (EARE) is described in section 2.1.4.

\subsubsection{Horizontal wind speed (HWS) method}

The HWS method requires the analysis of the Doppler shift of the backscattered signals. It is based on the analysis of the shape of hourly-averaged vertical wind speed profiles using the assumption that wind speed and wind direction are almost constant within the mixing layer but that the wind speed increases gradually towards the geostrophic value at the top of the mixing layer. BEYRICH (1997) listed this method in his Tab. 2 but does not discuss it further. The applicability of the method is due to the underlying assumptions probably limited to well-developed convective boundary layers (CBL). Such CBL are often higher than the maximum range of a SODAR. Even if the CBL height is within the range of the SODAR the algorithm for the analysis of the Doppler shift often fails above the inversion topping the CBL due to too low signal-to-noise ratios. Therefore this method is not considered here.

\subsubsection{Vertical wind variance ( VWV) method}

The VWV method is also working only for CBLs. It is based on the vertical profile of the variance of the vertical velocity profile $\sigma_{w}$. In a CBL $\sigma_{w}$ reaches a maximum in a height $a \cdot z_{i}$. Typical values for $a$ are between 0.35 and 0.4 . Thus, in principle, this is an extrapolation method. It has been tried for sodar measurements because it permits a detection of MLH up to heights which are 2.5 times above the limited maximum range (usually between 500 and $1000 \mathrm{~m}$ ) of the sodar. BEYRICH (1997) classifies this method as not reliable.

\subsubsection{Enhanced acoustic received echo (EARE) method}

The EARE algorithm proposed by EMEIS and TÜRK (2004) and EMEIS et al. (2007b) determines three different heights based on acoustic backscatter intensity and 
Table 1: Overview on methods using ground-based remote sensing for the derivation of the mixing-layer height mentioned in the sections (see rightmost column) of this paper.

\begin{tabular}{|c|c|c|c|}
\hline \multicolumn{2}{|l|}{ method } & \multirow{2}{*}{$\begin{array}{l}\text { short description } \\
\text { analysis of acoustic backscatter intensity profiles }\end{array}$} & \multirow{2}{*}{$\begin{array}{l}\text { section } \\
2.1 .1\end{array}$} \\
\hline acoustic & ARE method & & \\
\hline “ & HWS method & analysis of wind speed profiles & 2.1 .2 \\
\hline “ & VWV method & analysis of vertical wind variance profiles & 2.1 .3 \\
\hline “ & EARE method & $\begin{array}{l}\text { analysis of acoustic backscatter intensity and vertical wind } \\
\text { variance profiles }\end{array}$ & 2.1 .4 \\
\hline optical & threshold method & detection of a given backscatter intensity threshold & 2.2 .1 \\
\hline “ & gradient method & analysis of optical backscatter intensity profiles & 2.2 .2 \\
\hline “ & idealised backscatter method & analysis of optical backscatter intensity profiles & 2.2 .3 \\
\hline “ & wavelet method & analysis of optical backscatter intensity profiles & 2.2 .4 \\
\hline “ & variance method & analysis of optical backscatter intensity profiles & 2.2 .5 \\
\hline \multicolumn{2}{|c|}{ acoustic / electro-magnetic } & ARE method applied to sodar and wind profiler data & 2.3 .1 \\
\hline \multirow{2}{*}{\multicolumn{2}{|c|}{$\begin{array}{l}\text { acoustic / optical } \\
\text { acoustic / electro-magnetic / electro- } \\
\text { magnetic }\end{array}$}} & EARE method plus gradient method & 2.3 .2 \\
\hline & & $\begin{array}{l}\text { combination of a sodar-RASS and a wind profiler RASS: } \\
\text { analysis of the vertical temperature profile plus analysis of } \\
\text { the electro-magnetic backscatter intensity profile }\end{array}$ & 2.3 .3 \\
\hline \multicolumn{2}{|c|}{ acoustic / in situ } & ARE method plus in-situ surface flux measurement & 2.3 .4 \\
\hline
\end{tabular}

the variance of the vertical velocity component. Because the horizontal wind information above the inversion is not regularly available from SODAR measurements (see section 2.1.2 above), horizontal wind data have not been included into this scheme. The EARE algorithm determines:

- the height $(H 1)$ of a turbulent layer characterised by high acoustic backscatter intensities $R(z)$ due to thermal fluctuations (therefore having a high variance of the vertical velocity component $\sigma_{w}$ ),

- several lifted inversions $\left(H 2 \_n\right)$ characterized by secondary maxima of acoustic backscatter due to a sharp increase of temperature with height and simultaneously low $\sigma_{w}$, and

- the height of a surface-based stable layer (H3) characterised by high backscatter intensities due to a large mean vertical temperature gradient starting directly at the ground and having a low variance of the vertical velocity component.

The height $H 1$ corresponds to a sharp decrease $\partial R / \partial z<D R_{1}$ of the acoustic backscatter intensity $R(z)$ below a threshold value $R_{c}$ with height $z$ usually indicating the top of a turbulent layer:

$$
H 1=z, \quad \text { if } \quad\left(\begin{array}{c}
R(z)<R_{c} \\
\text { and } \quad R(z+1)<R(z)+z D R_{1} \\
\text { and } \quad R(z+2)<R(z)+2 z D R_{1}
\end{array}\right)
$$

$R_{c}=88 \mathrm{~dB}$ and $D R_{1}=-0.16 \mathrm{~dB} / \mathrm{m}$ have proven to be meaningful values in the abovementioned studies. $R_{c}$ is somewhat arbitrary because the received acoustic backscatter intensities from a SODAR cannot be absolutely calibrated. An absolute calibration would require the knowledge of temperature and humidity distributions along the sound paths for a precise calculation of the sound attenuation in the air. $D R_{1}$ is, at least for smaller vertical distances, independent from the absolute value of $R_{c}$. An application-dependent finetuning of $R_{c}$ and $D R_{1}$ may be necessary.

Elevated inversions are diagnosed from secondary maxima of the backscatter intensity that are not related to high turbulence intensities. For elevated inversions increase in backscatter intensity below a certain height $z=H 2$ and a decrease above is stipulated while the turbulence intensity is low:

$$
H 2 \_n=z, \quad \text { if }\left(\begin{array}{rr}
\left.\frac{\partial R}{\partial z}\right|_{z+1}<-D R_{2} \\
\text { and }\left.\frac{\partial R}{\partial z}\right|_{z-1}>D R_{2} \\
\text { and } \sigma_{w}<0.70 \mathrm{~ms}^{-1}
\end{array}\right)
$$

for $\mathrm{n}=1, \ldots, \mathrm{N}$. In EMEIS et al. (2007b) $\mathrm{N}$ was chosen to be five. A threshold value $D R_{2}=0.08 \mathrm{~dB} / \mathrm{m}$ has proven suitable. But again, an application-dependent tuning may be advisable. The determination of the height of the stable surface layer $\mathrm{H} 3$ is started if the backscatter intensity in the lowest range gates is above $105 \mathrm{~dB}$ while $\sigma_{w}$ is smaller than $0.3 \mathrm{~ms}^{-1}$. The top of the stable layer $\mathrm{H} 3$ is at the height where either the backscatter intensity sinks below $105 \mathrm{~dB}$ or $\sigma_{w}$ increases above $0.3 \mathrm{~ms}^{-1}$.

$$
\begin{array}{r}
H 3=z, \quad \text { if }\left(\begin{array}{ccc} 
& R(z) & >105 \mathrm{~dB} \\
\text { and } & R(z+1) & <105 \mathrm{~dB} \\
\text { and } & \sigma_{w}(z) & <0.3 \mathrm{~ms}^{-1}
\end{array}\right) \\
\text { or if }\left(\begin{array}{ccc} 
& \sigma_{w}(z) & <0.3 \mathrm{~ms}^{-1} \\
\text { and } & \sigma_{w}(z+1) & >0.3 \mathrm{~ms}^{-1} \\
\text { and } & R(z) & >105 \mathrm{~dB}
\end{array}\right)
\end{array}
$$

The $\sigma_{w}$ values used in (2.2) and (2.3) have been determined by optimizing the automatic application of the detection algorithm. In doing so it turned out that 
no lifted inversions occurred with a variance $\sigma_{w}$ lower than $0.7 \mathrm{~ms}^{-1}$ and that the variance $\sigma_{w}$ in nocturnal stable surface layers was below $0.3 \mathrm{~ms}^{-1}$. The first $\sigma_{w}$ threshold made it possible to distinguish between inversions and elevated layers of enhanced turbulence. The latter $\sigma_{w}$ threshold made it possible to differentiate between nocturnal stable surface layers and daytime superadiabatic surface layers although both types of surface layers yield more or less the same level of backscatter intensity. Finally MLH from the acoustic remote sensing is determined as the minimum of $H 1, H 2_{-} 1$, and $H 3$ :

$$
\mathrm{MLH}_{a c}=\min \left(H 1, H 2 \_1, H 3\right)
$$

\subsection{Optical detection of MLH}

Making the assumption that the vertical aerosol distribution adapts rapidly to the changing thermal structure of the boundary layer MLH can be determined from the analysis of this aerosol distribution. This includes the assumption that the vertical aerosol distribution is not dominated by advected aerosol layers. The heights of the near surface aerosol layers (H4_n) can be analysed from the optical vertical backscatter profile obtained from optical remote sensing. Several methods exist: (1) the threshold method, (2) the gradient or derivative method, (3) the idealised gradient method, (4) the wavelet method, and (5) the variance method.

The application of optical remote sensing for MLH determination has focussed on the use of ceilometers in recent years. Ceilometers can be regarded as a small LIDAR. They are simpler and they have a much lower lowest range gate than LIDARs. For the detection of MLH below 150 to $200 \mathrm{~m}$ a ceilometer with one optical axis for the emitted and the received beam should be used. Due to the thin light beams the overlap of the emitted and received beam from a ceilometer with two parallel optical axes can be insufficient in this height range. Further on, Doppler shifts are not analyzed by ceilometers. Therefore, in contrast to acoustic remote sensing with Doppler-Sodars, additional variables in addition to the backscatter intensity are not available from ceilometers for the design of determination schemes for MLH. Thus the schemes listed below all resemble to the ARE methods for acoustic remote sensing.

\subsubsection{Threshold method}

MELFI et al. (1985) and BoERs et al. (1988) used simple signal threshold values, though this method suffers from the need to define them appropriately (SICARD et al., 2006). H4 is defined here as the height within the vertical profile of the optical backscatter intensity where the backscatter intensity first exceeds a given threshold when coming downward from the free unpolluted troposphere. The determination of several heights $H 4 \_n$ would require the definition of several thresholds which probably cannot be done a priory to the analysis. Therefore this will always lead to a subjective analysis of MLH.

\subsubsection{Gradient or derivative methods}

HAYDEn et al. (1997) and Flamant et al. (1997) proposed to use the largest negative peak of the first derivative of the optical attenuated backscatter intensity $(B(z))$ for the detection of $H 4$ from LIDAR data (height of gradient minimum $H 4_{G M}$ ):

$$
H 4_{G M}=\min \left(\frac{\partial B(z)}{\partial z}\right)
$$

Likewise WulfMEYER (1999) used the first minimum of the slope to detect the top of a convective boundary layer from DIAL data. MÜNKEL and RÄSÄNEN (2004) and SCHÄFER et al. (2004, 2005) applied the gradient method to ceilometer data. MENUT et al. (1999) took the minimum of the second derivative of $B(z)$ as the indication for MLH:

$$
H 4_{I P M}=\min \left(\frac{\partial^{2} B(z)}{\partial z^{2}}\right)
$$

This method is called inflection point method (IPM). It usually gives slightly lower values for $\mathrm{H} 4$ than the gradient method (2.5). A further approach was suggested by SENFF et al. (1996). They looked for the largest negative gradient in the logarithm of the backscatter intensity (height of logarithmic gradient minimum $H 4_{L G M}$ ):

$$
H 4_{L G M}=\min \left(\frac{\partial \ln B(z)}{\partial z}\right)
$$

This approach usually gives the largest value for H4. According to SICARD et al. (2006) $H 4_{I P M}$ from (2.6) is closest to the MLH derived from radiosonde ascents via the Richardson method. The other two algorithms (2.5) and (2.7) give slightly higher values. A comparison is given in Fig. 1.

In EMEIS et al. (2007b) the gradient method (2.5) has been further refined and extended to enable the calculation of up to $n=5$ lifted inversions. This algorithm is described in the following. Prior to the determination of gradient minima the overlap and range corrected attenuated backscatter profiles have to be averaged over time and height to suppress noise generated artefacts. Therefore the $H 4$ values are determined in a two-step procedure. Between $140 \mathrm{~m}$ and $500 \mathrm{~m}$ height sliding averaging is done over $15 \mathrm{~min}$ and a height interval $\Delta \mathrm{h}$ of $80 \mathrm{~m}$. In the layer between 500 and $2000 \mathrm{~m} \Delta \mathrm{h}$ for vertical averaging is extended to $160 \mathrm{~m}$. Two additional parameters have been introduced to further reduce the number of false hits. The minimum accepted attenuated backscatter intensity $B_{\min }$ right below a lifted inversion is set to $200 * 10^{-9} \mathrm{~m}^{-1} \mathrm{sr}^{-1}$ in the lower layer and $250 * 10^{-9} \mathrm{~m}^{-1} \mathrm{sr}^{-1}$ in the upper layer. Additionally the vertical gradient value $\partial B / \partial z_{\max }$ of a lifted inversion must be more negative than $-0.30 * 10^{-9} \mathrm{~m}^{-2} \mathrm{sr}^{-1}$ in the lower layer and more negative than $-0.60 * 10^{-9}$ $\mathrm{m}^{-2} \mathrm{sr}^{-1}$ in the upper layer. 


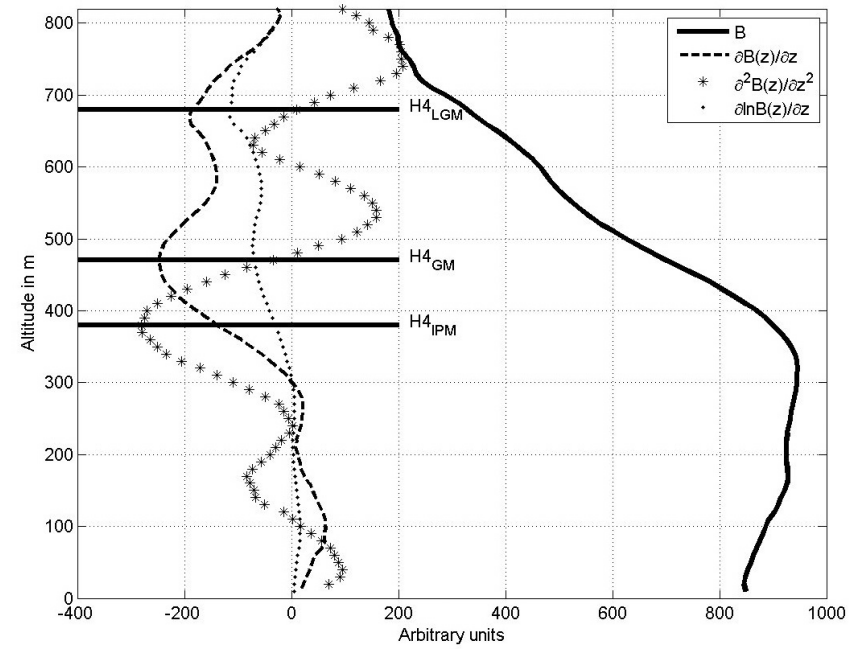

Figure 1: Schematic of the three gradient or derivative methods for MLH determination from optical remote sensing. B denotes the optical backscatter intensity.

If $B(z)$ denotes the measured attenuated backscatter intensity in the height $z$ above ground averaged over time and height and $\Delta \mathrm{h}$ is the height averaging interval, then the gradient $\partial B / \partial z$ in the height $z$ is calculated as

$$
\left.\frac{\partial B}{\partial z}\right|_{z}=\frac{B\left(z+\frac{\Delta h}{2}\right)-B\left(z-\frac{\Delta h}{2}\right)}{\Delta h}
$$

A gradient minimum is characterized by a change of sign from minus to plus of the second derivative of $B(z)$. The height interval under examination is searched from bottom to top for these gradient minima $H 4 \_n$.

The second derivative of $B(z)$ in the height $z$ is

$$
\left.\frac{\partial^{2} B}{\partial z^{2}}\right|_{z}=\frac{\left.\frac{\partial B}{\partial z}\right|_{z+\frac{\Delta h}{2}}-\left.\frac{\partial B}{\partial z}\right|_{z-\frac{\Delta h}{2}}}{\Delta h}
$$

There is a gradient minimum $H 4 \_n$ in the height $z$ if the second derivative of $B(z)$ one range gate below $z$ is not positive, if the second derivative of $B(z)$ in the height $z$ is positive, and if the false hit conditions mentioned above are fulfilled:

$$
H 4 \_n=z, \quad \text { if }\left(\begin{array}{ccl} 
& \left.\frac{\partial^{2} B}{\partial z^{2}}\right|_{z-1} & \leq 0 \\
\text { and } & \left.\frac{\partial^{2} B}{\partial z^{2}}\right|_{z} & >0 \\
\text { and } & B\left(z-\frac{\Delta h}{2}\right) & \leq B_{\min } \\
\text { and } & \left.\frac{\partial B}{\partial z}\right|_{z} & \leq \frac{\partial B}{\partial z} \text { max }
\end{array}\right)
$$

The MLH from optical remote sensing is taken as the lowest height H4_n:

$$
\mathrm{MLH}_{o p}=H 4_{-} 1
$$

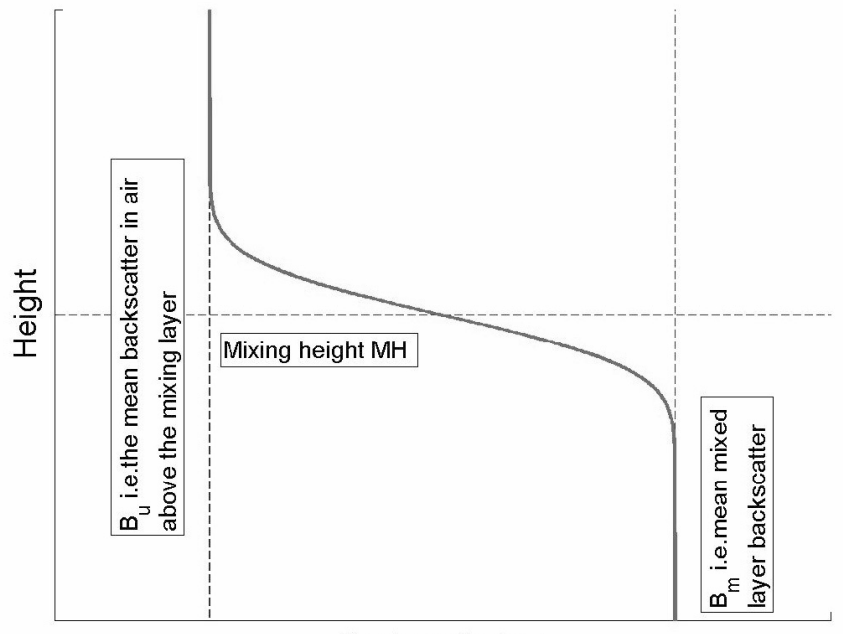

Backscattering

Figure 2: Schematic of the idealised gradient method from ERESMAA et al. (2006).

\subsubsection{Idealised backscatter method}

A parallel development by ERESMAA et al. (2006) using an idealised backscatter profile, originally described by STEYN et al. (1999), is also an extension of the gradient method. MLH is not determined from the observed backscatter profile, but from an idealised backscatter profile fitted to the observed profile. The robustness of this technique is founded on utilising the whole backscatter profile rather than just the portion surrounding the top of the mixing layer. In this method an idealized backscattering profile $B_{i}(z)$ is fitted to measured profile by the formula

$$
B_{i}(z)=\frac{B_{m}+B_{u}}{2}-\frac{B_{m}-B_{u}}{2} \operatorname{erf}\left(\frac{z-h}{\Delta h}\right)
$$

where $B_{m}$ is the mean mixing layer backscatter, $B_{u}$ is the mean backscatter in air above the mixing layer and $\Delta \mathrm{h}$ is related to the thickness of the entrainment layer capping the PBL in convective conditions (see Fig. 2). Two new parameters $\mathrm{A} 1$ and $\mathrm{A} 2$ are defined so that $A 1=\left(B_{m}+B_{u}\right) / 2$ and $A 2=\left(B_{m}--B_{u}\right) / 2$. The value of $A 1$ is kept constant during the fitting procedure. A good estimation of A1 based on an initial order-ofmagnitude guess for the MLH is crucial for the quality of the result. An idealised profile structure corresponding Eq. (2.12) is illustrated in Fig. 2. In this idealised case the backscatter above mixing layer and inside mixing layer have constant values $B_{u}$ and $B_{m}$ correspondingly and MLH is defined to be the height of the centre of the entrainment layer.

\subsubsection{Wavelet method}

A Wavelet method has been developed for the automatic determination of mixing layer height from backscatter profiles of an LD-40 ceilometer by de DE HAIJ et al. 
(2006). Before that wavelet transforms have been applied in recent studies for MLH determination from lidar observations (e.g. COHN and ANGEvine, 2000; DAVIS et al., 2000; BROOKS, 2003; WULFMEYER and JANJIĆ 2005). The most important advantage of wavelet methods is the decomposition of the signal in both altitude as well as vertical spatial scale of the structures in the backscatter signal.

The Wavelet algorithm in de DE HAIJ et al. (2006) is applied to the 10 minute averaged range and overlap corrected backscatter profile $B(z)$ within a vertical domain of 90-3000 m. For each averaged profile the top of two significant aerosol layers are detected in order to detect MLH as well as the top of a secondary aerosol layer, like e.g. an advected aerosol layer or the residual layer. This Wavelet MLH method uses the scale averaged power spectrum profile $W_{B}(b)$ of the wavelet transform with 24 dilations between 15 and $360 \mathrm{~m}$ and step size $15 \mathrm{~m}$. The top of the first layer, H4_1, is detected at the first range gate at which the scale averaged power spectrum $W_{B}(b)$ shows a local maximum, exceeding a threshold value of 0.1 . This threshold value is empirically chosen, based on the analysis of several cases with both well pronounced and less clearly pronounced mixing layer tops. $H 4 \_2$ is optionally determined in the height range between $H 4{ }_{-} 1$ and the upper boundary of detection. A valid $H 4 \_2$ is detected at the level with the strongest local maximum of $W_{B}(b)$ provided that this maximum is larger than the $W_{B}(b)$ of $H 4_{-} 1$. MLH is set equal to H4_1.

However, problems with this method arise e.g. in case of multiple (well defined) aerosol layers, which renders the selection of the correct mixing layer top ambiguous. Furthermore, in spring and summer the detection of the MLH for deep (convective) boundary layers often fails. This is mostly due to the high variability of the aerosol backscatter signal (see section 2.2.5 below) with height which limits the range for MLH estimation in those conditions (DE HAIJ et al., 2006).

\subsubsection{Variance method}

At the top of the convective boundary layer (CBL) we have entrainment of clear air masses from the free troposphere into the ABL. The entrainment process is temporarily variable and leads locally to considerable fluctuations in the aerosol concentration. Therefore the maximum in the vertical profile of the variance of the optical backscatter intensity can be an indicator for an entrainment layer on top a CBL (HOOPER and ELORANTA 1986; PIIRONEN and ELORANTA, 1995). The method is called variance centroid method in MENUT et al. (1999). The variance method for the CBL height is also described in LAMMERT and BÖSENBERG (2006). Due to the assumptions made this method is suitable for daytime convective boundary layers only. An elucidating comparison between the gradient method and the variance method can be found in MARTUCCI et al. (2004)

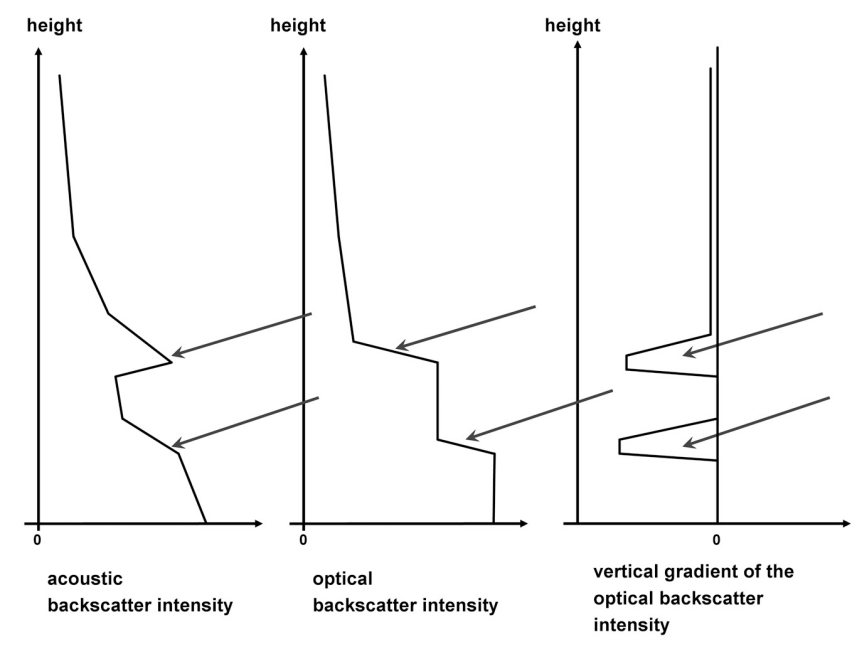

Figure 3: Schematic comparison of MLH determination algorithms in the case of a nocturnal stable surface layer and an elevated inversion above it. Left: vertical profile of acoustic backscatter intensity, middle: vertical profile of optical backscatter intensity, right: vertical profile of the vertical gradient of the optical backscatter intensity. Lower arrows mark the position of the height $H 3$ (left) and $H 4{ }_{-} 1$ (middle and right). Upper arrows mark the heights $H 2 \_1$ (left) and H4_2 (right). From EMEIS et al. (2007b).

although they used a Nd:YAG LIDAR at $532 \mathrm{~nm}$ instead of a ceilometer and thus suffered from a high lowest range gate in the order of $300 \mathrm{~m}$.

\subsection{Algorithms using more than one instrument}

Using more than one instrument for sounding can help to overcome some of the above described deficiencies of the individual instruments. Possible combinations are listed in the following subsections.

\subsubsection{Combined deployment of sodar and wind profiler}

BEYRICH and GÖRSDORF (1995) have reported on the simultaneous usage of a SODAR and a wind profiler for the determination of MLH. For the SODAR data the ARE method was used. From the wind profiler data MLH was likewise determined from the height of the elevated signal intensity maximum (see also ANGEVINE et al., 1994; GRIMSDELL and ANGEVINE 1998; WHITE et al., 1999). Good agreement between both algorithms was found for evolving convective boundary layers. The vertical ranges of the two instruments (50 to $800 \mathrm{~m}$ for the SODAR and 200 to $3000 \mathrm{~m}$ for the wind profiler) allowed following the complete diurnal cycle of MLH.

\subsubsection{Combined deployment of sodar and ceilometers}

There is an interesting difference between the schemes for the determination of MLH from acoustic and optical 
backscatter intensities which should be noted carefully (see Fig. 3). While the acoustic backscatter intensity itself is taken for the detection of $H 1$ and $H 3$ and the first derivative of this backscatter intensity for the determination of $H 2$, the first and the second derivative of the optical backscatter intensity (but not the optical backscatter intensity itself) is used to determine $H 4$. This discrepancy in the processing of the two backscatter intensities is due to the different scattering processes for acoustic and optical waves: Acoustic waves are scattered at atmospheric refractivity gradients and thus at temperature gradients (NEFF and COULTER, 1986) while optical waves are scattered at small particles. Therefore the optical backscatter intensity is proportional to the aerosol concentration itself. The MLH on the other hand, which we desire to derive from these backscatter intensities, is in both cases found in heights where we have vertical gradients of the temperature and of the aerosol concentration. Therefore, in principle, the vertical distribution of the acoustic backscatter intensity should look very much alike the vertical distribution of the vertical gradient of the optical backscatter intensity.

Simultaneous measurements with different remote sensing devices have mainly been made in order to evaluate one remote sensing method against the other (DEVARA et al. (1995). But one could also think of combining the results of two or more remote sensing devices for determining the structure of the ABL. Direct detection of MLH from acoustic backscatter intensities is limited to the order of about $1 \mathrm{~km}$ due to the rather high attenuation of sound waves in the atmosphere. In contrast, optical remote sensing offers much larger height ranges of at least several kilometres, because the attenuation of light waves in the atmosphere is small unless there is fog, clouds or heavy precipitation. A first combination of parallel measurements of the vertical structure of the atmospheric boundary layer by a ceilometer and a sodar is described in EMEIS and SCHÄFER (2006). This combination of SODAR and ceilometer offers the same advantages as the combination of SODAR and wind profiler presented in BEYRICH and GÖRSDORF (1995).

The analysis of the sodar data and the ceilometer data can be combined to one single piece of MLH information by forming the minimum from (2.4) and (2.11):

$$
\mathrm{MLH}=\min \left(\mathrm{MLH}_{a c}, \mathrm{MLH}_{o p}\right)
$$

\subsubsection{Combined deployment of two different RASS}

ENGELBART and BANGE (2002) have analyzed the possible advantages of the deployment of two RASS instruments, a SODAR-RASS (i.e. a SODAR with an electromagnetic extension) and a high-UHF WPR-RASS (i.e. a wind profiler with an additional sound source), to derive boundary layer parameters. With these instruments, in principle, MLH can either be determined from the temperature profiles or from the electro-magnetic backscatter intensity. The latter depends on temperature and moisture fluctuations in the atmosphere. The derivation of MLH from the temperature profile requires a good vertical resolution of the profile which is mainly available only from the SODAR-RASS. But even if the inversion layer at the top of the boundary layer is thick enough, due to the high attenuation of sound waves in the atmosphere, also the $1290 \mathrm{MHz}-W P R-R A S S$ used by ENGELBART and BANGE (2002) can measure the temperature profile only up to about $1 \mathrm{~km}$. Therefore, in the case of a deeper CBL, MLH was determined from a secondary maximum of the electro-magnetic backscatter intensity which marks the occurrence of the entrainment zone at the CBL top. Thus, with this instrument combination the whole diurnal cycle of MHL is ideally monitored by interpreting the temperature profile from the SODAR-RASS at night-time and by analyzing the electro-magnetic backscatter intensity profile from the WPR-RASS during daytime.

\subsubsection{Further algorithms using more than one instrument}

HENNEMUTH and KIRTZEL (2008) have recently developed a method that uses data from a sodar-RASS and surface heat flux data. MLH is primarily detected from the acoustic backscatter intensity received by the sodar part of the sodar-RASS and verified from the temperature profile obtained from the RASS part of the instrument. Surface heat flux data and statistical evaluations complement this rather complicated scheme. The surface heat flux is used to identify situations with unstable stratification. In this respect this observable takes over an analogous role as the $\sigma_{w}$ in the EARE algorithm (Ch. 2.1.4). The results have been tested against radiosonde soundings. The coincidence was good in most cases except for a very low MLH at or even below the first range gate of the sodar and the RASS.

\section{Conclusions}

Significant progress in determining MLH from groundbased remote sensing has been made in the last ten years. According to the desired application a choice between several options to determine and monitor MLH is possible today. The following main conclusions from this review may help with this decision:

Acoustic and electro-magnetic remote sensing is based on the thermal and moisture structure of the atmosphere while optical remote sensing relies on the aerosol distribution in the atmosphere. Thus, the algorithm for determining MLH from acoustic and electromagnetic data is more directly depending on meteorological parameters than the one from optical data, because the aerosol distribution has to adapt to the atmospheric stratification first.

Acoustic and optical remote sensing can be used today for stand-alone determination of MLH. Both techniques 
have suitable lowest range gates of $15 \mathrm{~m}$ (optical) and 20 to $60 \mathrm{~m}$ (acoustic). Optical remote sensing can follow the complete diurnal cycle while acoustic remote sensing suffers from the limited vertical range. Acoustic remote sensing is ideal for vertically high-resolution determination of shallow MLH (especially at night). Electromagnetic remote sensing is not suited for stand-alone operation due to the high lowest range gate which does not permit the coverage of shallow MLH. Stand-alone observations with a single RASS instrument are no solution because a SODAR-RASS has the same limited height range as a SODAR and a wind-profiler RASS has the same high lowest range gate as a wind-profiler.

Optical remote sensing techniques require clear skies. Low clouds, fog and rain obstruct the measurements. Acoustic remote sensing is obstructed by heavy rain and by ambient noise. Electro-magnetic techniques are most independent from environmental conditions.

Combinations of acoustic remote sensing together with optical and with electro-magnetic remote sensing offers the opportunity to follow the whole diurnal cycle of MLH even in spring and summer when deep CBLs frequently occur.

The use of acoustic remote sensing (SODAR and RASS) can annoy people. Safety distances of several hundreds of meters to housing are necessary. Therefore the application of these techniques in urban areas is difficult. On the other hand, eye-safety is essential for optical remote sensing in order to avoid permanent attendance during the measurements. Ceilometers are usually eyesave by construction. Electro-magnetic remote sensing needs some suitable shielding in order to avoid harm to people and interference with communication pathways operating in the same frequency band.

\section{Outlook}

Remote sensing of MLH is still a developing field because MLH is an urgently needed parameter in air quality studies, especially in studies relating to the environmental conditions in large cities, the living place of more than half of mankind. The technical development of remote sensing instruments using acoustic, optical, or electro-magnetic signals (or a combination of these) will continue.

The acoustic sounding technique, which is the oldest one, seems to be mature. Smaller additions to the existing algorithms for monitoring MLH are still possible. This refers especially to the simultaneous use of two or more variables in these algorithms. The optical sounding technique is still under development. Here, further miniaturization may be possible. Also the development of algorithms is still ongoing.

RASS instruments are presently the most ideal instruments for the detection of MLH because they record directly the temperature profile. A nearly perfect single instrument would be a SODAR-RASS with a sep- arate analysis of the electro-magnetic backscatter intensity because this backscatter intensity partly depends on the moisture fluctuations, too. Such an instrument has not been built so far because it would need separate evaluation procedures for the acoustic and electro-magnetic signals which would make the instrument rather expensive.

\section{References}

Angevine, W., A.B. White, S.K. Avery, 1994: Boundary layer depth and entrainment zone characterization with a boundary layer profiler. - Bound-Layer Meteor. 68, 375385.

Asimakopoulos, D.N., C.G. Helmis, J. MichopouLOS, 2004: Evaluation of SODAR methods for the determination of the atmospheric boundary layer mixing height. - Meteor. Atmos. Phys. 85, 85-92.

BEYRICH, F., 1995: Mixing height estimation in the convective boundary layer using sodar data. - Bound.-Lay. Meteor. 74, 1-18.

—, 1997: Mixing height estimation from sodar data - a critical discussion. - Atmos. Environ. 31, 3941-3953.

BEYRICH, F., U. GÖRSDORF, 1995: Composing the diurnal cycle of mixing height from simultaneous SODAR and Wind profiler measurements. - Bound.-Layer Meteor. 76, 387-394.

BoERS, R., J.D. SPINHIRNE, W.D. HART, 1988: Lidar Observations of the Fine-Scale Variability of Marine Stratocumulus Clouds. - J. Appl. Meteor. 27, 797-810.

BRoOKS, I.M., 2003: Finding boundary layer top: application of a wavelet covariance transform to lidar backscatter profiles. J. Atmos. Oceanic. Technol. 20, 1092-1105.

Cohn, S.A., W.M. Angevine, 2000: Boundary Layer Height and Entrainment Zone Thickness Measured by Lidars and Wind-Profiling Radars. - J. Appl. Meteor. 39, 1233-1247.

DABBERdT, W.F., M.A. CARroll, D. BAumgardner, G. CArmichel, R. Cohen, T. Dye, J. Ellis, G. Grell, S. Grimmond, S. HANnA, J. IRWin, B. LAMB, S. MAdronich, J. MCQueEn, J. MEAGHER, T. Odman, J. Pleim, H.-P. Schmid, D.L. WestPhal, 2004: Meteorological Research Needs for Improved Air Quality Forecasting. Report of the 11th Prospectus Development Team of the U.S. Weather Research Program. Bull. - Amer. Meteor. Soc. 85, 563-586.

Dandou, A., E. Bossioli, M. Tombrou, N. Sifakis, D. PARonis, N. Soulakellis And D. SARIGiannis, 2002: The importance of mixing height in characterising pollution levels from aerosol optical thickness derived by satellite. - Water Air Soil Poll. Focus 2, 17-28.

Davis, K.J., N. Gamage, C.R. HagelberG, C. Kiemle, D.H. LENSCHOW, P.P. Sullivan, 2000: An objective method for deriving atmospheric structure from airborne lidar observations. - J. Atmos. Oceanic. Technol. 17, 14551468.

de Haij, M., W. Wauben, H. Klein Baltink, 2006: Determination of mixing layer height from ceilometer backscatter profiles. - In: Remote Sensing of Clouds and the Atmosphere XI. Slusser, J.R.; K. SCHÄFER, A. COMERón (Eds.), Proceedings of the SPIE, Volume 6362, paper 63620R. 
Devara, P.C.S., P. ERnest Ray, B.S. Murthy, G. PANDithurAi, S. SHARMA, K.G. VERNEKAR, 1995: Intercomparison of Nocturnal Lower-Atmospheric Structure Observed with LIDAR and SODAR Techniques at Pune, India. - J. Appl. Meteor. 34, 1375-1383.

EMEIS, S., K. SCHÄFER, 2006: Remote sensing methods to investigate boundary-layer structures relevant to air pollution in cities. - Bound-Lay. Meteor. 121, 377-385.

EMEIS, S., M. TÜRK, 2004: Frequency distributions of the mixing height over an urban area from SODAR data. Meteorol. Z. 13, 361-367.

Emeis, S., C. Münkel, S. Vogt, W.J. Müller, K. SCHÄFER, 2004: Atmospheric boundary-layer structure from simultaneous SODAR, RASS, and ceilometer measurements. - Atmos. Environ. 38, 273-286.

EMEIS, S., M. HARRIS, R.M. BANTA, 2007a: Boundarylayer anemometry by optical remote sensing for wind energy applications. Meteorol. Z. 16, 337-347.

EMEis, S., C. JAhN, C. Münkel, C. Münsterer, K. SCHÄFER, 2007b: Multiple atmospheric layering and mixing-layer height in the Inn valley observed by remote sensing. - Meteorol. Z. 16, 415-424.

Engelbart, D.A.M., J. BAnge, 2002: Determination of boundary-layer parameters using wind profiler/RASS and sodar/RASS in the frame of the LITFASS project. - Theor. Appl. Climatol. 73, 53-65.

Engelbart, D., M. Kallistratova, R. Kouznetsov, 2007: Determination of the turbulent fluxes of heat and momentum in the ABL by ground-based remote-sensing techniques (a Review). - Meteorol. Z. 16, 325-335.

ERESMAA, N., A. KARPPINEN, S.M. JOFFrE, J. RÄSÄNEN, H. TAlvitiE, 2006: Mixing height determination by ceilometer. - Atmos. Chem. Phys. 6, 1485-1493, www.atmos-chem-phys.net/6/1485/2006/

Flamant, C., J. Pelon, P.H. Flamant, P. Durand, 1997: Lidar determination of the entrainement zone thickness at the top of the unstable marin atmospheric boundarylayer. Bound.-Layer Meteor. 83, 247-284.

Grimsdell, A.W., W.M. Angevine, 1998: Convective Boundary Layer Height Measurement with Wind Profilers and Comparison to Cloud Base. - J. Atmos. Ocean. Technol. 15, 1331-1338.

Hayden, K.L., K.G. Anlauf, R.M. Hoff, J.W. Strapp, J.W. Bottenheim, H.A. Wiebe, F.A. Froude, J.B. MARTin, D.G. SteYN, I.G. MCKEndRY, 1997: The Vertical Chemical and Meteorological Structure of the Boundary Layer in the Lower Fraser Valley during Pacific '93. J. Atmos. Environ. 31, 2089-2105.

Heimann D., De Franceschi M., Emeis S., Lercher P., Seibert P. (Eds.), 2007: Air Pollution, Traffic Noise and Related Health Effects in the Alpine Space - A Guide for Authorities and Consulters. - ALPNAP comprehensive report. Università degli Studi di Trento, Dipartimento di Ingegneria Civile e Ambientale, Trento, Italy, 335 pp. ISBN printed version: 978-88-8443-2087, ISBN electronic version: 978-88-8443-207-0 (available from: www.alpnap.org/results.html).

Hennemuth, B., H.-J. KiRtzel, 2008: Towards operational determination of boundary layer height using sodar/RASS soundings and surface heat flux data. - Meteorol. Z. 17, 283-296.

HoOper, W.P., E. ElorantA, 1986: Lidar measurements of wind in the planetary boundary layer: the method, accuracy and results from joint measurements with radiosonde and kytoon. - J. Clim. Appl. Meteor. 25, 990-1001.
LAMmert, A., J. BöSEnBERG, 2006: Determination of the Convective Boundary-Layer Height with Laser Remote Sensing. - Bound.-Lay. Meteor. 119, 159-170.

Martucci, G., M.K. Srivastava, V. Mitev, R. MATthey, M. Frioud, H. Richner, 2004: Comparison of lidar methods to determine the Aerosol Mixed Layer top. - In: Remote Sensing of Clouds and the Atmosphere VIII. Schäfer K., A. Comeron, M. CARleER, R.H. PICARD (Eds.), Proceedings of SPIE, Bellingham, WA, USA, 5235, 447-456.

Melfi, S.H., J.D. SpinhiRne, S.H. Chou, S.P. Palm, 1985: Lidar Observation of the Vertically Organized Convection in the Planetary Boundary Layer Over the Ocean. - J. Clim. Appl. Meteor. 24, 806-821.

Menut, L., C. Flamant, J. Pelon, P. H. Flamant, 1999: Urban Boundary-Layer Height Determination from Lidar Measurements Over the Paris Area. - Appl. Opt. 38, 945-954.

MÜNKEL, C., J. RÄSÄNEN, 2004: New optical concept for commercial lidar ceilometers scanning the boundary layer. - Proceedings of SPIE, Vol. 5571, 364-374.

NefF, W.D., R.L. Coulter, 1986: Acoustic remote sensing. Probing the Atmospheric Boundary Layer, D. H. Lenschow, (Ed.), Amer. Meteor. Soc., Boston, MA, 201239.

Pirronen, A.K., E.W. Eloranta, 1995: Convective boundary layer depths and cloud geometrical properties obtained from volume imaging lidar data. - J. Geophys. Res. 100, 25569-25576.

SCHÄFER, K., S.M. EMEIS, A. RAUCH, C. MÜNKel, S. VOGT, 2004: Determination of mixing-layer heights from ceilometer data. In: Remote Sensing of Clouds and the Atmosphere IX. SCH ÄFER K., A. COMERON, M. CARlEER, R.H. PICARD, N. SIFAKIS (Eds.), Proc. SPIE, Bellingham, WA, USA, Vol. 5571, 248-259.

SCHÄFER, K., S. EMEIS, W. JunkERMANN, C. MÜNKEL, 2005: Evaluation of mixing layer height monitoring by ceilometer with SODAR and microlight aircraft measurements. - In: Remote Sensing of Clouds and the Atmosphere X. , Schäfer K., A. Comeron, M. CARleEr, R.H. PICARD (Eds.), Proc. SPIE, Bellingham, WA, USA, Vol. 5979, 59791I-1-59791I-11.

SCHÄFER, K., S. EMEIS, H. HOFFMANN, C. JAHN, 2006: Influence of mixing layer height upon air pollution in urban and sub-urban area. - Meteorol. Z. 15, 647-658. DOI: $1 0 . 1 \longdiv { 1 2 7 / 0 9 4 1 - 2 9 4 8 / 2 0 0 6 / 0 1 1 6 . }$

SChäfer, K., A. Harbusch, S. Emeis, P. Koepke, M. WIEGNER, 2008: Correlation of aerosol mass near the ground with aerosol optical depth during two seasons in Munich. - Atmos. Environ. 42, 4036-4046.

Seibert, P., F. Beyrich, S.-E. Gryning, S. JofFre, A. RASMUSSEN, P. TERCIER, 2000: Review and intercomparison of operational methods for the determination of the mixing height. - Atmos. Environ. 34, 1001-1027.

SenfF, C., J. Bösenberg, G. Peters, T. Schaberl, 1996: Remote Sesing of Turbulent Ozone Fluxes and the Ozone Budget in the Convective Boundary Layer with DIAL and Radar-RASS: A Case Study. - Contrib. Atmos. Phys. 69, 161-176.

Sicard, M., C. Pérez, F. Rocadenbosch, J.M. BalDASANO, D. GARCÍA-VIZCAINO1, 2006: Mixed-Layer Depth Determination in the Barcelona Coastal Area From Regular Lidar Measurements: Methods, Results and Limitations. - Bound.-Lay. Meteor. 119, 135-157. 
Sifakis, N., N. Soulakellis, D. PARONIS, 1998: Quantitative mapping of air pollution density using Earth observations: a new processing method and application to an urban area. - Intern. J. Rem. Sens. 19, 3289-3300.

Steyn, D.G., M. BALDI, R.M. Hoff, 1999: The detection of mixed layer depth and entrainment zone thickness from lidar backscatter profiles. - J. Atmos. Ocean. Technol. 16, 953-959.

White, A.B., C.J. SenfF, R.M. Banta, 1999: A Comparison of Mixing Depths Observed by Ground-Based Wind
Profilers and an Airborne Lidar. - J. Atmos. Oceanic Technol. 16, 584-590.

WULFMEYER, V., 1999: Investigation of turbulent processes in the lower troposphere with water-vapor DIAL and Radar-RASS. - J. Atmos. Sci. 56, 1055-1076.

WULFMEYER, V., T. JANJIĆ, 2005: 24-h observations of the marine boundary layer using ship-borne NOAA HighResolution Doppler Lidar. - J. Appl. Meteor. 44, 17231744. 